THE PICKY EAGLE 



\section{THE PICKY EAGLE}

How Democracy and Xenophobia

Limited U.S. Territorial Expansion

RICHARD W. MAASS 
Copyright (C) 2020 by Cornell University

All rights reserved. Except for brief quotations in a review, this book, or parts thereof, must not be reproduced in any form without permission in writing from the publisher. For information, address Cornell University Press, Sage House, 512 East State Street, Ithaca, New York 14850. Visit our website at cornellpress.cornell.edu.

First published 2020 by Cornell University Press

Printed in the United States of America

Library of Congress Cataloging-in-Publication Data

Names: Maass, Richard W., author.

Title: The picky eagle : how democracy and xenophobia limited U.S. territorial expansion / Richard W. Maass.

Description: Ithaca : Cornell University Press, 2020. Includes bibliographical references and index.

Identifiers: LCCN 2019025912 (print) | LCCN 2019025913 (ebook) | ISBN 9781501748752 (hardcover) | ISBN 9781501748769 (epub) | ISBN 9781501748776 (pdf)

Subjects: LCSH: Democracy-United States-History. | Xenophobia_-Political aspects-United StatesHistory. | United States-Territorial expansionHistory. | United States-Foreign relations.

Classification: LCC E179.5 .M124 2020 (print) | LCC E179.5 (ebook) | DDC 320.0973-dc23

LC record available at https: / / lccn.loc.gov/ 2019025912

LC ebook record available at https://lccn.loc. gov/ 2019025913 
For Etuna 
